\title{
Factors affecting the assay of gentamicin by the plate diffusion method
}

\author{
SUSAN DEACON
}

From the Department of Bacteriology, The Middlesex Hospital Medical School, London

SYNOPSIS Standard curves were prepared by plotting log gentamicin concentration against zone diameter using a conventional plate diffusion method. Results were obtained at varying concentrations of sodium chloride and at different pHs. Under optimum conditions the range in zone diameters was markedly increased, thus considerably improving the potential accuracy of the plate assay method.

The aminoglycoside antibiotic gentamicin is widely used, particularly in cases of serious Gram-negative septicaemia. Its main drawback is its ototoxicity, and serum levels need to be closely monitored not only to prevent overdosage but also to ensure adequate therapeutic levels (Noone et al, 1974).

Rapid methods are available for the assay of serum gentamicin. The chemical method of Smith et al (1972) is based on an enzyme which catalyses the adenylation of gentamicin by radioactively labelled ATP. The amount of ${ }^{14} \mathrm{C}$-adenylated gentamicin is measured in a scintillation counter. An assay based on the inhibition by gentamicin of the urease activity of Proteus mirabilis has been described by Noone et al (1971). The advantage of these methods is that results can be obtained within about two hours, but they require specialized equipment. Therefore most laboratories still use conventional plate diffusion methods.

Since any microbiological method is subject to a considerable amount of error it is important to perform the assay under optimum conditions. In this article the possiblity of increasing the accuracy of the plate diffusion method by altering the constituents of the assay medium has been investigated. The theoretical implications are discussed.

\section{Material and Methods}

ASSAY ORGANISMS

Staphylococcus aureus (NCTC 6571) and Klebsiella edwardsii (NCTC 10896) were used as test organisms. Overnight cultures wer grown in Todd Hewitt broth (Oxoid).

Received for publication 26 June 1975.

\section{ASSAY MEDIUM}

Bacto antibiotic medium 2 (Difco) was used as the assay medium, having a final $\mathrm{pH}$ of 6.6 . This was supplemented with $0.5 \%, 1 \%, 1.5 \%$, and $2 \%$ sodium chloride where appropriate. The $\mathrm{pH}$ of the medium was adjusted by the addition of concentrated sodium hydroxide immediately before pouring the plates in order to prevent hydrolysis during autoclaving.

\section{PLATE DIFFUSION ASSAY}

Twenty-five millilitre volumes of assay medium were dispensed into $9 \mathrm{~cm}$ diameter plastic Petri dishes, giving a depth of about $4 \mathrm{~mm}$. A sample of the overnight culture was diluted in distilled water and plates were surface seeded with this suspension.

\section{GENTAMICIN STANDARDS}

Gentamicin sulphate (Genticin Injectable, Nicholas Laboratories) standards were prepared at concentrations of $2 \cdot 5,5,10,20$, and $40 \mu \mathrm{g}$ of gentamicin base per millilitre in pooled human serum and stored frozen.

\section{Results}

EFFECT OF SODIUM CHLORIDE ON THE STANDARD CURVE

Each plate was seeded with approximately $2 \times 10^{6}$ organisms. Six wells, $9 \mathrm{~mm}$ in diameter, were cut in each plate. To each of five wells was added $0.15 \mathrm{ml}$ of standard, one well remaining empty. Three replicate plates were used for each salt concentration. Diffusion time was less than 10 minutes and incubation was from 16 to 18 hours at $37^{\circ} \mathrm{C}$. The 
diameters of the zones of inhibition were measured to the nearest $0.5 \mathrm{~mm}$.

When plates were seeded with Klebsiella the range of zone diameters between 2.5 and $40 \mu \mathrm{g}$ of gentamicin per $\mathrm{ml}$ increased from $3 \mathrm{~mm}$ in the absence of sodium chloride to $9.8 \mathrm{~mm}$ at $1.5 \%$ sodium chloride (fig 1). Plates seeded with staphylococcus showed an increase in range over the same antibiotic concentrations from $4.8 \mathrm{~mm}$ without sodium chloride to 14 $\mathrm{mm}$ at $1.5 \%$ sodium chloride (fig 2 ). At a concentration of $2 \%$ sodium chloride the $2.5 \mu \mathrm{g} / \mathrm{ml}$ zones

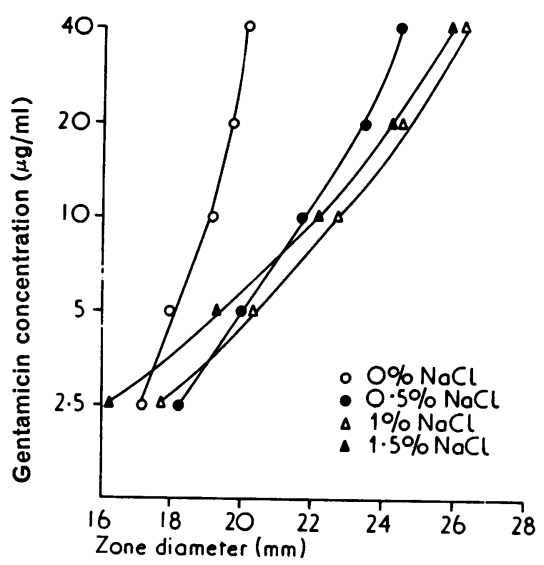

Fig 1 Effect of sodium chloride on standard curves for gentamicin obtained by a plate diffusion method using Klebsiella edwardsii (NCTC 10896) as the test organism.

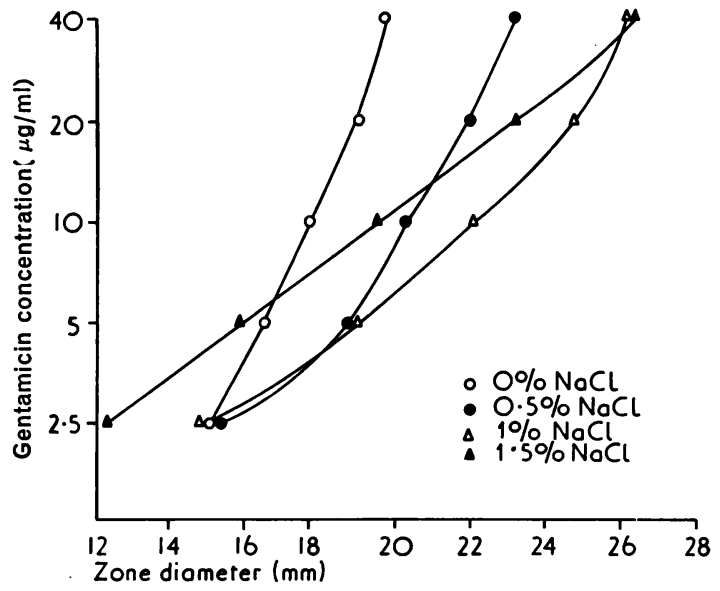

Fig 2 Effect of sodium chloride on standard curves for gentamicin obtained by a plate method using Staphylococcus aureus (NCTC 6571) as the test organism. were either non-existent or too small to be measured accurately.

The results shown are from a single experiment but the procedure has been repeated several times with essentially the same results.

EFFECT OF PH ON THE STANDARD CURVE

Plates were seeded with staphylococcus and, using the above procedure, standard curves were obtained at pHs ranging from 6.5 to 10 in the absence of added salt (fig 3). At pH 10 the growth of the bacteria was

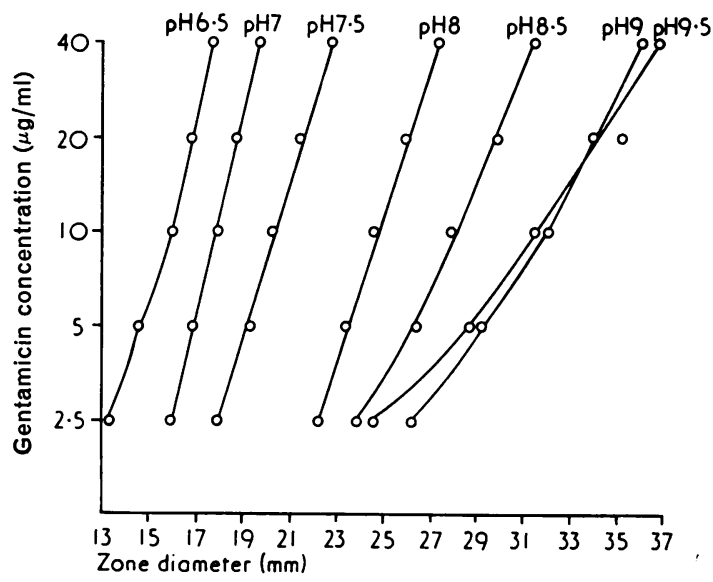

Fig 3 Effect of $\mathrm{pH}$ on standard curves for gentamicin obtained by a plate diffusion method using Staphylococcus aureus (NCTC 6571) as the test organism.

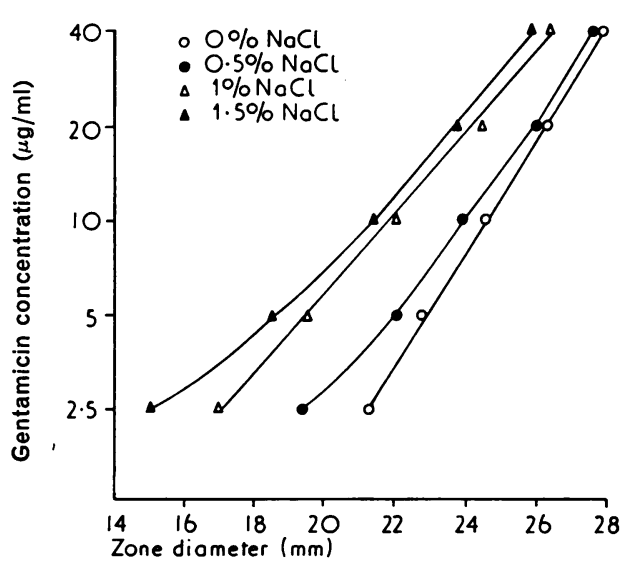

Fig 4 Effect of sodium chloride on standard curves for gentamicin obtained by a plate diffusion method at $\mathrm{pH} 9$, using Klebsiella edwardsii (NCTC 10896) as the test organism. 
affected and the standard curve was not satisfactory. Similar results were obtained when plates were seeded with Klebsiella. When the $\mathrm{pH}$ of the agar was adjusted to $\mathrm{pH} 9$ and supplemented with $0 \cdot 5,1$, and $1.5 \%$ sodium chloride the zone sizes produced were too large to be measured on a $9 \mathrm{~cm}$ plate. In order to reduce the zone sizes the diameter of the wells was reduced to $6.5 \mathrm{~mm}$ and the volume of standard to $0.09 \mathrm{ml}$ per well. This gave satisfactory results for plates seeded with Klebsiella (fig 4) but the zone sizes on staphylococcus-seeded plates were still too large. This was partially overcome by seeding the plates with $9 \times 10^{6}$ organisms (fig 5). However, at a sodium chloride concentration of $1.5 \%$ there was no zone for the $2 \cdot 5 \mu \mathrm{g} / \mathrm{ml}$ standard.

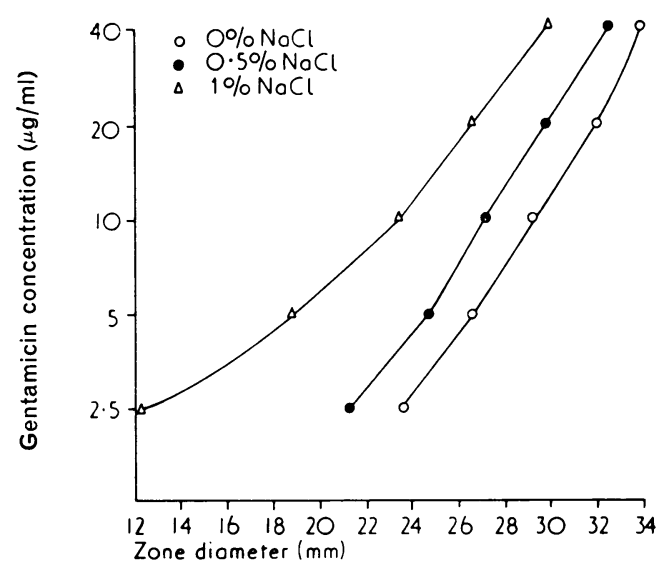

Fig 5 Effect of sodium chloride on standard curves for gentamicin obtained by a plate diffusion method at pH9, using Staphylococcus aureus (NCTC 657l) as the test organism.

\section{Discussion}

The choice of assay organism depends on the urgency of obtaining a result and on other antibiotics present in the serum.

Klebsiella (NCTC 10896) is resistant to most common antibacterial drugs which are likely to be prescribed in combination with gentamicin (Garrod et al, 1973). It is also fast growing, and zone sizes may be read after only about four hours' incubation. A salt concentration of $1.5 \%$ does not appear to inhibit the growth rate, but a high $\mathrm{pH}$ does have an inhibitory effect. Staphylococcus (NCTC 6571) tended to produce sharper zone edges than the Klebsiella but is sensitive to antibiotics such as lincomycin, which it is almost impossible to remove by pretreatment of serum. Treatment of serum with a B-lactamase would allow this organism to be used for the assay of gentamicin in the presence of those antibiotics which are inactivated by the enzyme. Another disadvantage in using staphylococcus is that it requires a longer period of incubation.

Plates were surface seeded because when preseeded agar was used the zone diameter decreased with increasing depth of the agar, presumably due to gentamicin being less active under anaerobic conditions. However, a thin layer of pre-seeded agar should be satisfactory.

By supplementing the assay medium with a sodium chloride concentration of $1.5 \%$ the range in zone diameters is increased approximately three-fold. This greatly enhances the potential accuracy of the plate assay method. There was loss of linearity at the higher salt concentrations but this was so slight that it was considered unimportant.

Comparison of the increase in range of zone diameters between plates at $\mathrm{pH} 6.6$ and $\mathrm{pH} 9$ (figs 1 and 4, and figs 2 and 5) shows that there is little advantage in using the higher $\mathrm{pH}$, at least when using $9 \mathrm{~cm}$ diameter Petri dishes. The range would probably be further increased using $9 \mathrm{~mm}$ wells and larger Petri dishes, but this was thought to be uneconomical. The fact that smaller volumes of serum may be used when assaying at pH 9 may be useful in cases where the amount of test serum is limited. The assay at $\mathrm{pH} 9$ would require only $0.27 \mathrm{ml}$ of serum, but even at the lower $\mathrm{pH}$ only $0.45 \mathrm{ml}$ would be needed.

There are several reports in the literature which state that increasing salt concentration has an inhibitory effect on the bactericidal action of gentamicin (Rubenis et al, 1963; Schoutens and Yourassowsky, 1972). This is thought to be due to competition between gentamicin and the other cations for binding sites on the bacterial surface (this author, unpublished results). Inhibition is certainly evident when the bacteria are growing in a liquid medium, and this is presumably why commercial media recommended for plate diffusion assays do not contain sodium chloride. However, $\widetilde{N}$ when bacteria are grown on solid media, this inhibi- $N$ tory effect is not apparent at high concentrations of N gentamicin. In fact, concentrations of sodium chlo- 0 ride up to $1 \%$ appear to enhance the bactericidal activity of the drug at amounts above $5 \mu \mathrm{g} / \mathrm{ml}$. The $\stackrel{\circ}{=}$ reason for this is uncertain but since the action of $\stackrel{\Phi}{\oplus}$ gentamicin is very much dependent on the metabolic : state of the bacteria (this author, unpublished results), a possible explanation is that the bacteria themselves are more susceptible to gentamicin at $\frac{\pi}{\mathbb{D}}$ higher salt concentrations. Thus the sodium chloride $\varrho$ is simultaneously both enhancing and inhibiting the 
action of gentamicin, the extent of each effect being dependent on the concentration of the drug.

In contrast, increasing $\mathrm{pH}$ gives rise to larger zones at all concentrations of the drug, although there is an approximately two-fold increase in the range. It is also possible that increasing $\mathrm{pH}$ may affect the susceptibility of the bacteria to gentamicin. While a high $\mathrm{pH}$ enhances the activity of gentamicin it also reduces the rate of growth of the organisms, and this accounts for the fact that at $\mathrm{pH} 9$ salt is inhibitory at all concentrations of gentamicin.

I am grateful to Dr R. E. M. Thompson for helpful advice in the preparation of this paper, and I would also like to thank Miss Susan Lockwood for typing the manuscript.

\section{References}

Garrod, L. P., Lambert, H. P., and O'Grady, F. (1973). Antibiotic and Chemotherapy, 4th ed., p. 528. Churchill Livingstone, Edinburgh and London.

Noone, P., Parsons, T. M. C., Pattison, J. R., Slack, R. C. B., Garfield-Davies, D., and Hughes, K. (1974). Experience in monitoring gentamicin therapy during treatment of serious gram-negative sepsis. Brit. med. J., 1, 477-481.

Noone, P., Pattison, J. R., and Samson, D. (1971). Simple, rapid method for assay of aminoglycoside antibiotics. Lancet, 2, 16-19.

Rubenis, M., Kozij, V. M., and Jackson, G. G. (1963). Laboratory studies on gentamicin. Antimicrob. Agents and Chemother., 3, 153-156.

Schoutens, E. and Yourassowsky, E. (1972). Effets du chlorure de sodium sur l'activité antistaphylococcique de la gentamicine. Path. et Biol., 20, 947-949.

Smith. D. H., Van Otto, B., and Smith, A. L. (1972). A rapid chemical assay for gentamicin. New Engl. J. Med., 286, 583-586. 